\title{
Oriental Marco Polo Plaza Encounter: Choreographing Place and Placelessness from a Phenomenological Perspective
}

\author{
Huihui Gao * and Shangyi Zhou * \\ Faculty of Geographical Science, Beijing Normal University, Beijing 100875, China \\ * Correspondence: gaohuixingfu@hotmail.com (H.G.); shangyizhou@bnu.edu.cn (S.Z.); \\ Tel.: +86-131-2180-3022 (H.G.); +86-139-1002-0509 (S.Z.)
}

check for updates

Citation: Gao, H.; Zhou, S. Oriental Marco Polo Plaza Encounter: Choreographing Place and

Placelessness from a

Phenomenological Perspective. Sustainability 2021, 13, 6159. https:// doi.org/10.3390/su13116159

Academic Editors:

Alessandra Fermani and Isabella Crespi

Received: 25 March 2021

Accepted: 26 May 2021

Published: 30 May 2021

Publisher's Note: MDPI stays neutral with regard to jurisdictional claims in published maps and institutional affiliations.

Copyright: (C) 2021 by the authors. Licensee MDPI, Basel, Switzerland. This article is an open access article distributed under the terms and conditions of the Creative Commons Attribution (CC BY) license (https:// creativecommons.org/licenses/by/ $4.0 /)$.

\begin{abstract}
The notion of place has raised great concern within weaving tourism studies in recent decades. Nevertheless, dialectical indigenous considerations of Edward Relph's phenomenological concepts of place and placelessness are still insufficient, particularly in non-Western countries. Phenomenology, as an immersive approach, provides an open and descriptive examination of the diverse perceptions and constitutive meanings of a place. From a phenomenological perspective, this article aims to explore the dynamic grasping of place and placelessness in tourism experiences. Twenty-four tourists participated in the research in Marco Polo Plaza in Italian Style Town, a concession for a particular historical period, in Tianjin, China. The findings suggest that tourists' experiences could be ordered into three themes: (1) encountering a place labelled recreation and entertainment, (2) encountering an exotic heterogeneous place, and (3) encountering a lived place in the lifeworld. These results emphasize that place and placelessness are intertwined paradoxically beyond the binary, and such a nonlinear, dialectical, and subtle dimension is the possible inspiration that the phenomenological perspective brings to tourism research. Drawing on the inevitability of tourists' diverse perceptions, we advance that an open multi-sensuous engagement and inclusive geographic practices offer an insight into the understanding of sustainability.
\end{abstract}

Keywords: tourism experience; place; placelessness; phenomenological approach

\section{Introduction}

" ... the task of geography is conceived as the establishment of a critical system which embraces the phenomenology of landscape, in order to grasp all its meanings..."

\section{Carl Sauer [1]}

Geographers are generally interested in landscape phenomena. As a subdiscipline of geography, tourism geography, with its extensive descriptive phenomenological engagement, has emerged as a way to rethink the nature of tourism and sustainability [2,3]. It considers the understandings, experiences, and perceptions of a place [4,5]; contributes abundant argumentations on contradictions and unsolved problems between attachment/identity and alienation/rupture [6-8]; and embraces tourism experience-related topics such as vulnerability, imbalance, gender, and authenticity [9-12].

Tourists encounter heterogeneous destinations, and their sensual perception of the similarities and differences of various places invites diverse meanings constantly, which is reflected in the phenomenological concepts of place and placelessness advocated by the humanistic geographer Edward Relph [13]. The two concepts, proposed nearly half a century ago, muse an ensuing spurt in researches of the notion of place, and radiate to various realms such as human geography, landscape architecture, city planning and environmental psychology. The implications of both concepts have been enriched over time, especially placelessness, which echoes the concept of non-place later proposed [14] and 
inspires a critique of elitism in the process of globalization, capitalism, and consumerism that induces spatial homogeneity, such as issues of airports, theme parks, shopping centers, chain stores, and the current common phenomenon of social welfare housing. However, it is necessary to develop the two concepts from a tourism perspective. In his classic, place and placelessness, Relph himself basically cares about places from a tourist's perspective. Without such "floating eyes", there can be little comparison between place and placelessness.

Place means particularity and locality, while placelessness is blandness and similarity. Both attempt to approach the extremes of landscape regenerations [13,15]. Interestingly, we also find this phenomenon in contemporary mainstream discourses of oriental tourism studies, which are always accompanied by an exotic and mysterious sense that differs from that of the West against the background of its unique history and culture. Therefore, relevant studies are mostly subordinate to the "place", and emphasize the differences between East and West [16]. At the same time, we note that most non-Western-related studies consistently wander at the edge, and seem slightly plain, weak and pale, especially in this homogenized world with a technological shock and capital domination. This tendency thus becomes a footnote to the notion of "placelessness" - a flat, meaningless mode [17]. Such research, however, is obscure; it calls for the need to capture the significance of indigenous tourist landscapes to reveal visitors' understanding, participation, and shaping of place in this domain [18].

Based on descriptive experience and the phenomenological method, this study aims to explore the dynamic grasping of place and placelessness in tourism experience as a meaning-generating complex. We conducted a field survey of 24 tourists at Marco Polo Plaza in Tianjin, China, which is a hybrid place, neither a purely original surrounding nor an attempt to create a completely illusory space or simulacrascape. It is authenticity that exists in an inauthentic environment-the authentic Mediterranean architecture is distantly embedded in the east, built and preserved for particular historical events. The blurring of the boundary between authenticity and inauthenticity is a challenge to tourists in terms of both cognition and aesthetics.

This article attempts to address the following questions after the investigation: is it a necessity to consider the binary opposition between place and placelessness in the study of indigenous tourism? If placelessness is far from important, does place still make sense? How are the meanings grasped dynamically in tourism? This study contributes to dialectical conceptualizations of place and placelessness and discussions of embodied tourism experiences. Here, it is worth noting that we focus on sustainability mostly from a micro point of view (a scale of urban blocks). In this article, materials, landscapes, and activities are tangible forms in which such sustainability connotations are represented.

\section{Literature Review}

\subsection{Place and Placelessness in Human Geography}

The encounter between tourists and places involves a phenomenology in which specific groups of people endow a milieu with distinctive meanings and emotions [19]. According to humanistic geographer E. Relph, there are two aspects of such encounters [16]. One is a sense of place, a shared memory of a named place. It is the manifestation of order that integrates environmentalism and existentialism, and establishes a spatial center of lived experience that can generally be identified at various scales (body, county, city, or country) and in different categories (home, pubs, or the wild) [20-22]. The other aspect is that place becomes flat and monotonous with unification and standardization in the process of modernization; this is known as placelessness, an ingenious concept proposed by Relph, and followed by Buttimer, and Seamon [23]. Placelessness is considered a weakened sense of place accompanied by the weakening of diverse experiences and identities that are embedded in the declining process of cultural diversity in different places, which not only "look the same", but also potentially give rise to possible homologous emotions and experiences in tourism [24]. With the increasing fluidity of the homogenization process, the bond between humans and indigenous history is probably either perturbed or even 
erased. Therefore, the proliferation of cookie-cutter and unreal placelessness implies, to some extent, disintegration and disappearance of place [23].

Compared with a static point of view, the meanings of place and placelessness grow gradually and continuously. Traditional attitudes about being rooted in a place give a way to popular perceptions of place mobility and diversity. However, the boundary between the two concepts has become blurred and indistinguishable with the continuous progress of globalization, as claimed in Relph's later works [17]. Both the change in people's preferences and the compression of time and space have brought about unprecedented rich experiences. The duality of the positive and negative presented in the 1970s is less clear in the postmodern era. To understand a place is to understand its similarities with other places. That is, when we emphasize placelessness, we are also reaffirming the uniqueness of place, and vice versa [17].

It is noteworthy that both of the concepts, place and placelessness, are discussed from an existentialist phenomenological perspective. Openness and infinity are crucial to understanding the concept of place. According to Relph, "both geography and place are, at their core, phenomena of experience that can best be explicated phenomenologically" [13]. He, therefore, argues that phenomenology, as a method of research, seeks to clarify complexity rather than reduce the world to some simple Cartesian model. In place studies, it is not advisable to easily put aside or abandon the method of phenomenology. Massey advocates the global sense of place and regards the phenomenological method as a point to exacerbate place inequality, while according to Relph, it is a mistake to consider place as a site of nostalgia involving boundaries, exclusion, and aggravating inequality. The phenomenological perspective maintains that place is an "everyday phenomenon" fundamentally and "precedes all academic concepts and explanations" because place is open, boundless, and dialectical [13].

\subsection{Place and Placelessness in Tourism Context}

Many studies have examined the tension between place and placelessness. Tourism can be regarded as a movable feast of people and place, because tourism landscapes in different places both hold and repair people's memories and stimulate and satisfy curiosity during life's journey [25]. It is neither easy nor pleasant to expose one to everemerging attractions in utterly strange surroundings or to wander in a placeless world meaninglessly [4].

Tourism activities help people to capture the specific spirit of place, or genius loci; to have a deeper understanding of the differences and similarities between different places; and to acquire a sense of internal, belonging, and place attachment. Thus, the lifeworld is unfolded. In tourism research, tourists, residents, and the interaction between the two highlight the sustainability, resilience, and competitiveness of the human environment relationship at the destination [26]. Over the years, the number of indigenous studies has increased. Lee et al. take the demilitarized zone of Korea as a case to explore tourists perceived similarities and shared beliefs that reflect the key values of sustainable tourism in regard to place [27]. In addition, industrial heritage tourism in China has also attracted the attention of researchers, especially residents, whose active participation promotes their connection with place, thus generating attachment to place and contributing to the development of local tourism [28]. Apart from the separate focus on visitors and residents, the emotional solidarity generated by their interactions increases the number of revisits [29]. In the multinatural Anthropocene, Schilar et al. focuses on the embodied connection between tourism actors and nature in outdoor activities from a more-than-human perspective in northern Sweden [30]. In this study, travel activities are permeated with lifestyle entrepreneurship and fused with place attachment and perception of tourists, constituting a unique emotional connection between people and place. The tourists' body and mind get rest and shelter here, which in turn induces them to revisit the destination frequently. Above all, physical setting, activities, and meanings, the three crucial components according to Relph, are combined when visiting a place [13]. 
In recent years, one of the "high aged themes" that has been retained and discussed by tourism researchers is placelessness, as a faded place identity in the modernization process [17]. Apart from Disneyfied and museumized places mentioned by Relph, attention has been flooded with a fantasy, a capital-commercial space, such as an airport and a shopping mall, which emphasize a universal, artificial, and placeless atmosphere [14,31,32]. Shim and Santos give the eastern city of Seoul as an example to investigate the relationship between place and placelessness, and highlight the shopping malls in Seoul that offer visitors a placeless atmosphere and new appeal [31]. They found that the homogenization of places in the context of globalization is also the fracture between people and social culture. It is the production of a tourism landscape driven by mobility in the era of mass tourism. This kind of landscape does not reflect the indigenous characteristics, but the inauthentic landscape is the manifestation of the discontextualized meaning and place. Interestingly, functional and tasteless commercial spaces become more recognizable due to regional features of the items they sell, as well as the aesthetic environmental decorations. At the McDonald's in the airport in Beijing, for example, passengers can taste local traditional snacks such as soy milk and Youtiao (a traditional fried Chinese bread) that would be beyond imagination at a McDonald's at Heathrow or Kennedy Airport.

In addition, the influence of technology on contemporary tourism cannot be underestimated. Armed with ICT and media, the contemporary visitors have extended their "tentacles" (not just travelling around with a camera in Relph's early writing age). At the same time, tourists have greater expressive power, and the meaning of tourism and mobility has been conceptualizing. Therefore, compared with early visitors who were more impressed with authenticity in order to realize differences, modern encounters are more independent and choosy, accustomed to using the word 'encounter' in their own way to cope with the same or different. Baler et al., based on phenomenology, taking travel writers in the digital era as research objects, explored the influence of technology and media on the business interaction model, brand model and capability model of tourism, and emphasized the changes of the right interaction process of tourism experience in the era of social media [33].

These studies have intensively examined place and placelessness in the context of tourism. However, due to the limited research on the mutual involvement of the two concepts, this article attempts to draw on them anew. Phenomenological engagement in sustainable tourism constitutes the starting point of our study.

\section{Method}

\subsection{Phenomenology as a Method}

The phenomenological approach has established a descriptive and interpretive paradigm for the study of phenomena [34]. As a resist against Cartesian mind-body dualism, Husserl's phenomenology emphasizes the procedural nature of strict description in an attempt to seek the "essence" of the thematic structure of perception [35]. It is concerned with being, being-in-the-world, perception, the lifeworld and lived experience, in particular, it recognizes the intentionality of human action and body-subject, and the understanding of the rhythm of time and space through the exploration of intersubjectivity [36-38]. The philosophy, in which nature and culture are intertwined, and subject and object are integrated, provides a fresh and subtle perspective for insight into all aspects of social life [39]. Phenomenological methods have been widely used in all aspects of tourism research, especially in understanding tourist experiences [40]. Due to the eclecticism presented in this methodology, the specific methods adopted by researchers vary in both theoretical reflection and case studies (usually based on transcendental phenomenology, interpretive phenomenology, psychological phenomenology, etc.) $[9,16,41-43]$. Although there is probably no general conduct, most studies have attempted reduction and bracketing.

This article follows the phenomenological research method proposed by the geographer Relph, which consists of three steps. First, the essence of the object is summarized through the description. At this point, the essence is not accuracy, but the researcher's 
intention to make a rough identification, that is, to propose a general impression. Second, specific descriptions and judgments are made on the constituted phenomena, focusing on the correlation and interaction between each phenomenon. The third step is to describe the theme. It is to compress and reduce consciousness and attitudes, thus providing opportunities to highlight the research theme and solve the research problems.

\subsection{Research Area}

The research area was Italian Style Town with Marco Polo Plaza as its center, where the main interviews were conducted. The town is a rectangular area surrounded by four roads in the district [44]. A Roman column is at the center of the plaza with a bronze statue on top of the goddess of peace, holding an olive branch in her hand, symbolizing the eternal theme of friendship and peace, constituting an architectural space that combines practicality and aesthetics.

The research area, as a city block, has been shifting its preference of sustainability with the development of the times. These preferences do not mean the complete turn or essential change of sustainability itself, but the continuous accumulation of the connotation of sustainability, making it richer, providing more perceptual, cognitive, aesthetic and emotional resources for people who care about it, understand it and discuss it. It was originally the Italian Concession in the early 20th century with a complicated socio-political context and discourses on space and power [45,46]. With the establishment of the socialist country and the recovering of sovereignty, the buildings here have been preserved and developed in accordance with local conditions to make use of their unique historical and cultural resources [47]. In 1986, Tianjin's Urban Master Plan stipulated that the city center mainly developed commerce, foreign trade, and financial industry [48]. From 2005 to 2020, the new Urban Master Plan delineated four functional zones along Hai River, shown in Figure 1. The historic site of the former Italian Concession is located in the Entertainment and Tourism Area in the plan.

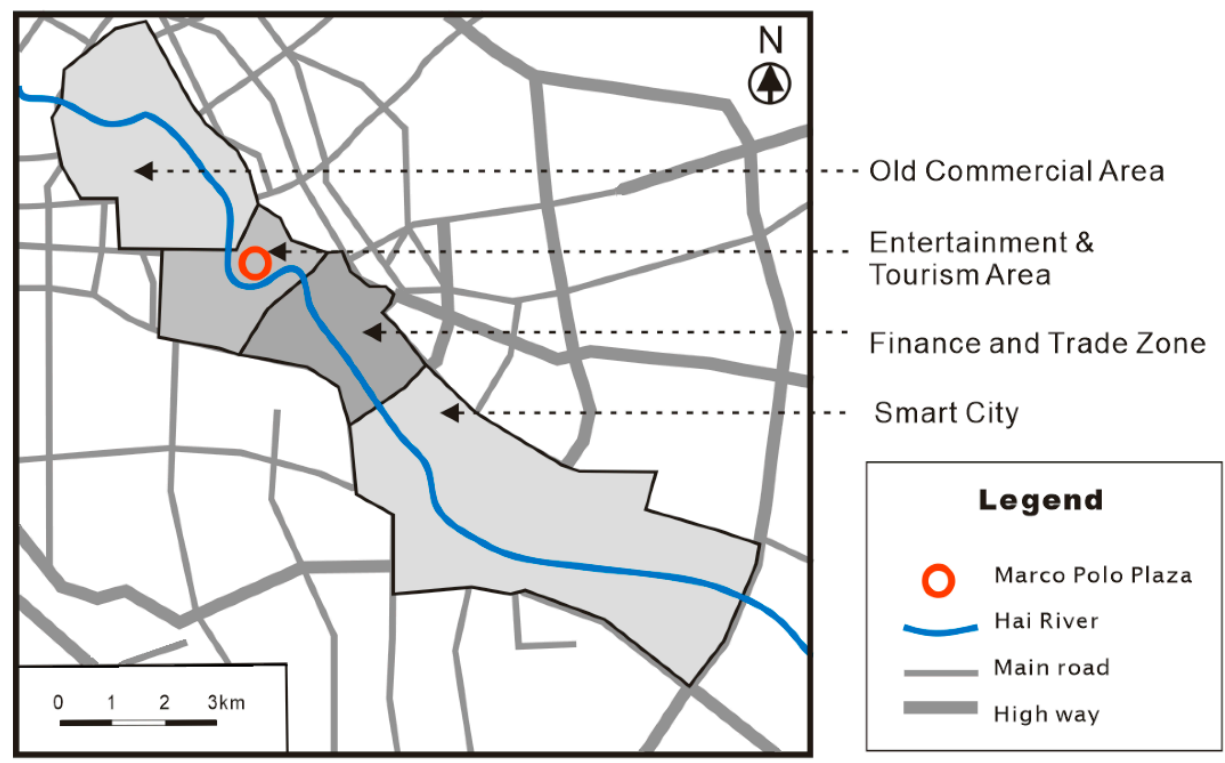

Figure 1. The four functional zones in the central city of Tianjin.

\subsection{Data Collection and Analysis}

In this paper, phenomenological methods are used to conduct semi-structured interviews with 24 tourists (Table 1). It is worth noting that the sample size is a crucial issue in the research process. Additionally, the number of participants we selected in the study seems high for the phenomenological method, because, firstly, as is known, different from quantitative research that should meet requirements and sampling standards of statistics, 
phenomenology is a typical qualitative research that focuses on the original lived world, so it pays more attention to people's experiences. Through epoché, the researcher tries to find out the essence of the interaction between people and the world as well as the shared meanings from the perspective of interviewees [49]. Another reason is that the practical process of phenomenological research is open. According to different research phenomena, the researcher chooses different numbers of interviewees, data collection materials and time and duration needed [50]. As is said, "the more complex the phenomenon is, the larger the number of interviewees will be" [51]. What this means is that we can follow one or two participants over a period of time, and also a number of people can be interviewed to collect limited materials in a relatively short term. Specific to this study, in view of the historical and functional diversity of the study area itself, especially the impact of seasonality on tourism activities, the authors conducted a three-year survey (2018-2020), with 4 trips, and 6 tourists interviewed randomly each time. In order not to cause too much disturbance to the visitors' schedule, the time for each person is limited to 20 to 40 min. Therefore, in view of the characteristics of qualitative research, the complexity of the phenomenon, the randomness of tourists, and the instantaneousness of the interview content (no follow-up interview was conducted later), up to 24 interviewees participated in this study.

Table 1. Participants.

\begin{tabular}{cccc}
\hline PARTICIPANTS & AGE & $\begin{array}{c}\text { GENDER } \\
\text { (MALE/FEMALE) }\end{array}$ & $\begin{array}{c}\text { CITIZENSHIP } \\
\text { ((NON/)LOCAL) }\end{array}$ \\
\hline P1 & 28 & $\mathrm{M}$ & $\mathrm{N}$ \\
P2 & 48 & $\mathrm{M}$ & $\mathrm{N}$ \\
P3 & 26 & $\mathrm{~F}$ & $\mathrm{M}$ \\
P4 & 45 & $\mathrm{~F}$ & $\mathrm{~N}$ \\
P5 & $\mathrm{F}$ & $\mathrm{N}$ \\
P6 & $\mathrm{F}$ & $\mathrm{N}$ \\
P7 & 22 & $\mathrm{~F}$ & $\mathrm{~L}$ \\
P8 & 41 & $\mathrm{M}$ & $\mathrm{L}$ \\
P9 & 19 & $\mathrm{M}$ & $\mathrm{N}$ \\
P10 & 37 & $\mathrm{~F}$ & $\mathrm{~N}$ \\
P11 & 29 & $\mathrm{~F}$ & $\mathrm{~N}$ \\
P12 & 30 & $\mathrm{M}$ & $\mathrm{N}$ \\
P13 & 38 & $\mathrm{~F}$ & $\mathrm{~L}$ \\
P14 & 35 & $\mathrm{M}$ & $\mathrm{N}$ \\
P15 & 18 & $\mathrm{~F}$ & $\mathrm{~N}$ \\
P16 & 41 & $\mathrm{~F}$ & $\mathrm{~N}$ \\
P17 & M & $\mathrm{L}$ \\
P18 & 45 & $\mathrm{M}$ & $\mathrm{N}$ \\
P19 & 24 & $\mathrm{~F}$ & $\mathrm{~N}$ \\
P20 & 30 & $\mathrm{~F}$ & $\mathrm{~L}$ \\
P21 & 43 & $\mathrm{M}$ & $\mathrm{N}$ \\
P22 & 25 & $\mathrm{~F}$ & \\
P23 & 31 & & P24 \\
\hline
\end{tabular}

At the end of each interview, participants were given a Beijing-Opera-Mask-themed magnet as a token of appreciation. All of the interviewees were adults (although some participants take their children, and the interview is inevitably processed with the occasional interaction between them, we still recognize acknowledge and respect the independence and leading role of adult respondents in this research), with equal numbers of men and women. Tourists fall into two main categories based on their sources: Tianjin local tourists and non-local tourists. Among the non-local, there are tourists from other regions of China and worldwide. Some of them come here frequently, while others are visiting for the first time. Among the non-local tourists, first-time visitors are mostly international. The topics 
in the interview relate to the tourists' sense of place, including imagination, impression, expectation, and multi-sensory perception, and dialogues mainly on function, emotion, globalization, materiality, and embodiment, which are abstract and open, to encourage the participants to describe their lived and immersive travel experiences.

This article follows three phenomenological steps. First, the basic work during the interview was to record the respondents' answers. After the interview, the audio-recorded materials were converted into texts for the convenience of follow-up analysis. We further classified and simplified these complex materials into different categories, which is the first step of Relph's phenomenological method. Second, meaning units were identified to illustrate the dynamic and hybrid characteristics of place perception, rather than narratives on tourist activities in a broad sense. This de-texturized process corresponds to the second step of Relph's phenomenological method. The third step was to describe the themes; related subjects were themed and described by the author.

\section{Findings}

In the following, we present a themed description of the topic categories. Based on meaning units from materials, we identified three interwoven themes: (1) encountering a place labelled recreation and entertainment, (2) encountering an exotic heterogeneous place, and (3) encountering a lived place in the lifeworld. Among them, the second theme, exoticism, consists of two subthemes: consumption and aesthetic. These results highlight the immersive phenomenological experience in exploring hybrid places in the oriental Marco Polo Plaza, which makes it possible to generate a diversity of encounters and to courage us to re-recognize and consider the paradox of place and placelessness.

\subsection{Encountering a Place Labelled Recreation and Entertainment}

A place that has been labelled recreation and entertainment may directly differentiate itself from other places and highlight its uniqueness. This is evident in the visitors' functional recognition of the place in interview materials [52]:

"We are making great efforts to develop and construct along the Haihe River in Tianjin, especially with the active promotion of tourism. Marco Polo Plaza is just located on its north bank, and the surrounding area has also been designated as a domestic key cultural relic protection unit. The Plaza is such a pearl on the Haihe River. Definitely, the restoration and reconstruction project is huge" (P23)

At the same time, the label brings a stronger identity to the local and stimulates relevant emotional experiences [53]. During our interviews, we found that local tourists, as insiders, were fond of using words such as "Tianjinese" or "an icon of Tianjin", and often distinguished between "we (local tourists)" and "they (non-local tourists)" in their narratives: "as an old Tianjinese, I usually spend the whole day there on weekends, drinking and talking...it is adjacent to Laolongtou railway station and is quite friendly for tourists to come to visit" (P4). However, as outsiders, non-local visitors may be likely to find more problems and arguments related to issues that the local taken for granted: "...what makes me curious and confused is how the themes of recreation and patriotism coexist here, and what kind of atmosphere will be created, so here I am" (P5).

In addition, labelling a place in urban planning can rapidly ferment, radiate, and spread to distant places via the Internet in today's information age, booming a postmodern phenomenon and thus becoming an effective means to attract investment and tourists:

"Marco Polo Square is much more famous than I thought. Before I came here, I looked at several tourist attraction recommendation-related apps and travel guide websites, and the Plaza ranked very high. There was a lot of discussion from people who used traditional travel notes, photos, Gopro and even drones to create memorable experiences, and most of them thought it was a perfect place to relax" (P20) [54] 
Thus, it can be seen that the labelled place provides tourists with direction-oriented intuitions in terms of functions and atmosphere, which is easy to arouse the emotions expected by the space designers. It allows visitors to focus their intention and expectation on a specific environment, catering to Selby's advocacy for a better understanding of the urban tourist experience space [4]. At the same time, the labelled place verifies the brand strategy that Hoffmann believes strengthens the uniqueness of the place, imposes the stereotype of the place, and then achieves the successful attraction and flow of tourists [55]. This approach seems to have already rooted in people's minds in depth-the planning scheme of urban planners or designers is the discourse and representation, which has the role of performance mentioned by Hall, which is undoubtedly in the influence or shaping of the behavior of tourists [56].

In modern society, however, boundaries have been broken down, and the explosiveness of information flow has become a dilution of uniqueness. During the survey, we found that many tourists have a calm and cool attitude towards the "leisure" label. Labelling, they say, is too much and nothing new. As one respondent said,

"Travel fever has become a fashion in China today. You'll find tourist slogans everywhere, on highway billboards, on buses, on the electronic screens of waiting rooms of high-speed railway stations filled with tourist towns, all-area tours, farmhouses, tourist city image videos, and all kinds of homestays with strange themes. Of course, we've become used to all these labels, and I'm even immune to them" (P10)

Obviously, the place is no longer typical: "I think this tag is very thin, and I have always learned a lot about the introduction and features through the Internet" (P10). As a result, places with various labels become placeless, kitsch, murmuring, filling the journey like background music. These labels sparkle around tourists' activities like a mosaic, but they do not constitute a de facto attraction to a place.

Tagged placelessness makes tourists realize their independence, and they are more willing to travel as subjects and to make independent choices. They "only go where they want to go and have no interest in being advertised" (P8), "In fact, as an incredibly relaxing place, I enjoy a tiny Trevi fountain (Figure 2), hold a glass of beer, listen to the joyful sound of running water to music, chat with my love until sunset, and feel like I'm in a movie, say, Roman Holiday. It's so romantic" (P22). This shows that tourists prefer to experience with their own senses and pay more attention to the process of travel instead of being led by dazzling labels to blindly and passively pursue a placeless space designed by others. Nevertheless, who knows if this so-called freedom is also potentially designed?

\subsection{Encountering an Exotic Heterogeneous Place}

One of the most attractive charms of the area is exoticism. The exotic and heterogeneous space has become Shangri-La in tourists' minds, satisfying their curiosity about others and about indigenous cultures, and bringing physical and mental pleasure and romantic experiences $[57,58]$. These exotic amorous feelings are first reflected in the eyecatching tourist destination of the physical space. One visitor said, "The unique European architectural style is very impressive. Walking along the cobbled and tiled streets, you will find that even street lamps, street signs, telephone booths and fruit boxes are all designed in exotic styles, combining romance and warmth with a strong Mediterranean flavour" (P12). 


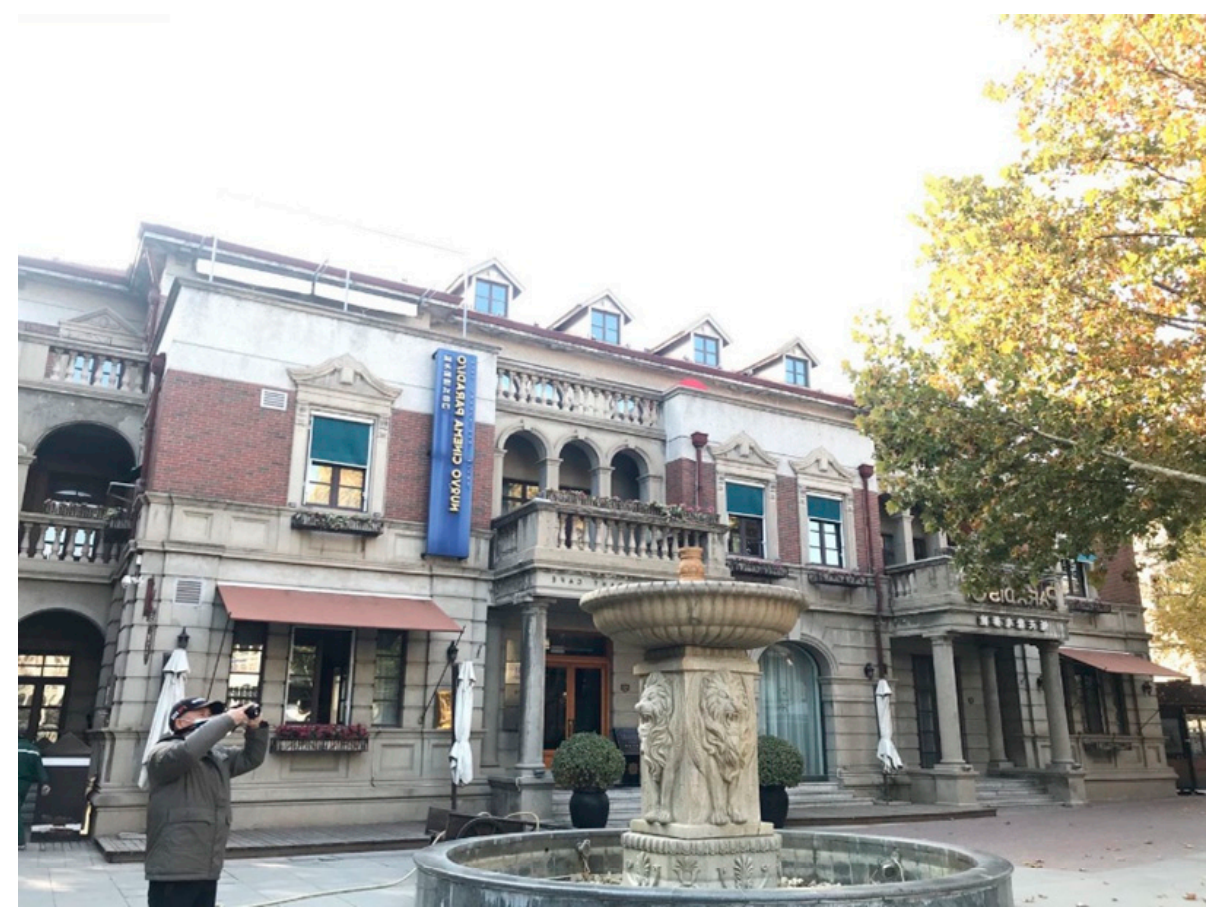

Figure 2. Trevi Fountain. (The photo was taken by the author).

Uncovering the veil of romanticism, we can also identify the slightly indefinable scent of transnational space, which envelops the description of some tourists' travel experience and is related to the spirit of the times [59]. Some of the descriptions of tourists' travel experiences are shrouded in this aura, which may have something to do with the zeitgeist:

“When looking at these townhouses, I can't help recalling recent historical events. I have mixed feelings, East and West, war and friendship...As we all know, this area is the product of a former concession area for a special history...Today, these buildings are very well preserved, so I'm lucky to be here... I like it not just because it's beautiful but because of its real, thick, and historic past...." (P21)

The external space of matter leads us to think beyond the architectural text, and the exotic physical space takes us to a more-than-architectural text.

Exoticism is also embedded in the interviewees' narratives, as shown in the following examples:

"Italy in my mind is a country of romance, of Romeo and Juliet. It's also a country of tasty food. Fortunately, there was more than I had expected, such as spaghetti and pizza dancing on my taste buds, the intoxicating opera, and postcards of the Leaning Tower of Pisa which I bought as a souvenir. My journey is almost finished, but I still hope to encounter a handsome boy, either in a restaurant or just on the corner of a path ...." (P3)

"At night, the street blossoms its exquisite and charming facets. I often meet my friends or my wife, talking or whispering with the moonlight. There is always a cosy feeling in the air, and the worries of my work and life disappear now and then...." (P4)

"I'm a travel genius. Three years ago, I went to Italy and visited Rome, Verona, and Venice. So I feel very kindly and familiar when I come as if I had gone back to the happy and unforgettable time...." (P14)

Heterochrony and heterotopy create a spatial atmosphere during the tour, which does not seem to be entirely an explicit and unambiguous call for visitors to Fernandes's hedonistic or western-style urban lifestyle [60]. Instead, the atmosphere veils mystery over 
these particular materials, revealing the spatiotemporal compression of social relationships that Harvey advocates, and makes these particular materials emotionally and meaningfully ambiguous [61]. The spatiotemporal interlacing inevitably brings various vibrant exotic experiences to tourists. People wander in a trance between the authentic and the inauthentic, between places of memory, places of history and places of contemporary reality, and between Eastern and Western civilizations. At the same time, the distinction between place and placelessness is dissolved into invisibility: "Actually, I don't really know why I come here, maybe for the landscape, maybe the feeling, or something else...." (P21)

\subsubsection{Consumption}

Unlike most tourist towns, Marco Polo Plaza does not float in the inauthentic fantasy of nothingness, descending to a gauzy heap of inconsequential elements. On the contrary, as a former concession, the intervention of foreign culture makes the atmosphere of this place not abrupt and inconsistent, but more inclusive and colorful; it becomes a consumption place where global and local goods are integrated [62] (Figure 3). During our research, we found many symbols of foreign elements and replicas of landmark buildings in various countries. For example, the model of the Eiffel Tower in France was placed in front of a restaurant named "La Seine". In the making of places that have been deeply influenced by consumerism, people will take the initiative to mix these symbolic elements into new forms, and then re-create a new place [63].

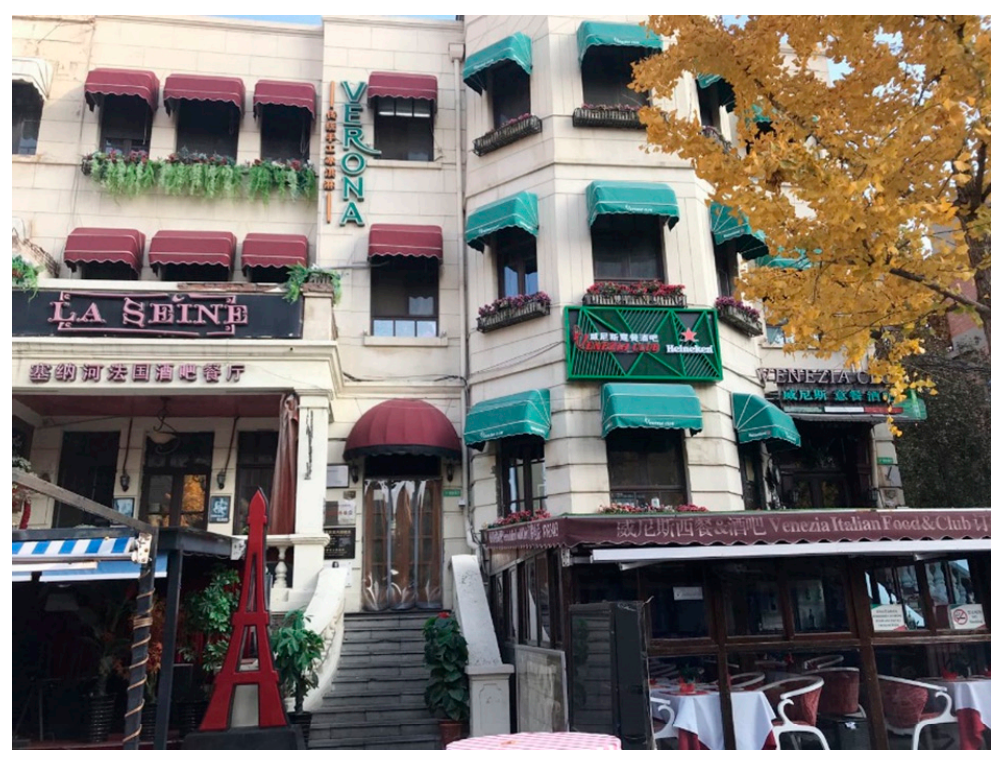

Figure 3. Restaurants in the street. (The photo was taken by the author).

"I found a lot more here than I expected, especially for food," said one visitor. "Besides pizza and pasta, there are Pattaya's Thai Food, Bavarian Beer, Provence Restaurant...these all have imaginative decorations...the chic beer barrels, the charming lights in the shop at night, the voice with different styles...all the phenomena here looks so fascinating!" (P17)

Another tourist was surprised to see Go Believe (狗不理包子), a famous local steamed bun in Tianjin. "It's amazing to find such a local store in this bustling and exotic place, local food mix with the food from all over the world!" (P18)

Some people, however, think that the homogenized landscape formed under the effect of the market mechanism described by $\mathrm{O}^{\prime} \mathrm{Brien}$ and Harris is undoubtedly a representation of placelessness [64]. The "standardized" and "mediocre" products to be sold create temporary, low-paid jobs in tourism and entertainment, and also may lead consumers to lose their interests in the destination, which is a reflection of placelessness $[65,66]$. 
"There seems to be nothing special here compared with the consumption in other tourist cities, because the goods for sale can be bought anywhere else, especially via the Internet." (P24) One tourist said, "There is a sense of consumerism in the air, and the art of architecture is diluted by the atmosphere of capital and pleasure. The colourful neon lights at night give us an illusion of another Las Vegas...there are a lot of places like this. It's disappointing," and "many of the small goods in the shops here are common in most tourist attractions, which cannot help but feel a little boring. How can I have such a strong desire to buy?" (P24).

From the restaurant names that include place names worldwide, we have a glimpse of the oriental Marco Polo Plaza, a heterogeneous travel space that has become a mixture of place and placelessness, deeply reshaped in time and space due to the influence of globalization and modernization [67]. The hybridity of symbols and elements around the world generates new places and is integrated into tourist experiences. Such authentic Mediterranean architecture has emerged in China, including short streets with all kinds of food and small goods from the distant world, which is not only a mixture of material, but also the interweaving of culture. From tourists' narratives of placelessness, it is not difficult to see that globalization has already penetrated people's daily lives. The development of communication technology and the popularization of the Internet make it easy to join every place and other parts of the world. Commodities break the regional block, and are realized and transported on a global scale, which may be enough to quench the thirst of curious tourists, but may increase their boredom with gradually homogeneous places as well. However, the reality may also be that, as Byung-Chul Han said, people's excessive pursuit in the negative impoverishment only increases their boredom with place [68].

\subsubsection{Aesthetic}

"I like it very much. It's a paradise of eclecticism, all kinds of sculptures, beautiful fairies, little angels, the statue of Marco Polo, the Dante statue, fountains...they not only complement the neighbourhood environment, but also enrich the cultural connotation together with the classic statue of Peace in the middle of the plaza, making people linger and forget to return [69] ... I particularly like the sculpture of the Flower Fairy (Figure 4). The beautiful fairies, emerging from the water, lift the basket of various colourful flowers, and naturalism overwhelms the romanticism of the area...." (P15)

"The streets of the Italian Concession are decorated with stone pavements, neat rows of trees and garden villas, and the end of the visual corridor features a Statue of Dante or a Roman pillar as the focal point" (P11)

One of the popular alleys hidden behind the villa is called Anghiari, with shops featuring the concept of "creative boutique". Above the entrance door, the name is inscribed in large red letters with exquisitely carved flowers, and wall lamps with a European style adorn the walls on both sides of the alley. "I really like the Renaissance name of Anghiari, which is very stylized, a typical 'European-style Alley, Exotic Alley'" (P11). Visitors enjoy the beauty of the architecture as they walk through it. From the doorway, one can also overlook the corner towers of the surrounding buildings of the plaza, bringing a sense of "scenery within scenery", which becomes one of the classic images in the area. Through the multisensory experiences of a large number of sculptures, architecture and other dynamic materials, tourists' geographical imaginations are aroused, making the oriental Marco Polo Plaza the impact of global aesthetic taste [70]. 


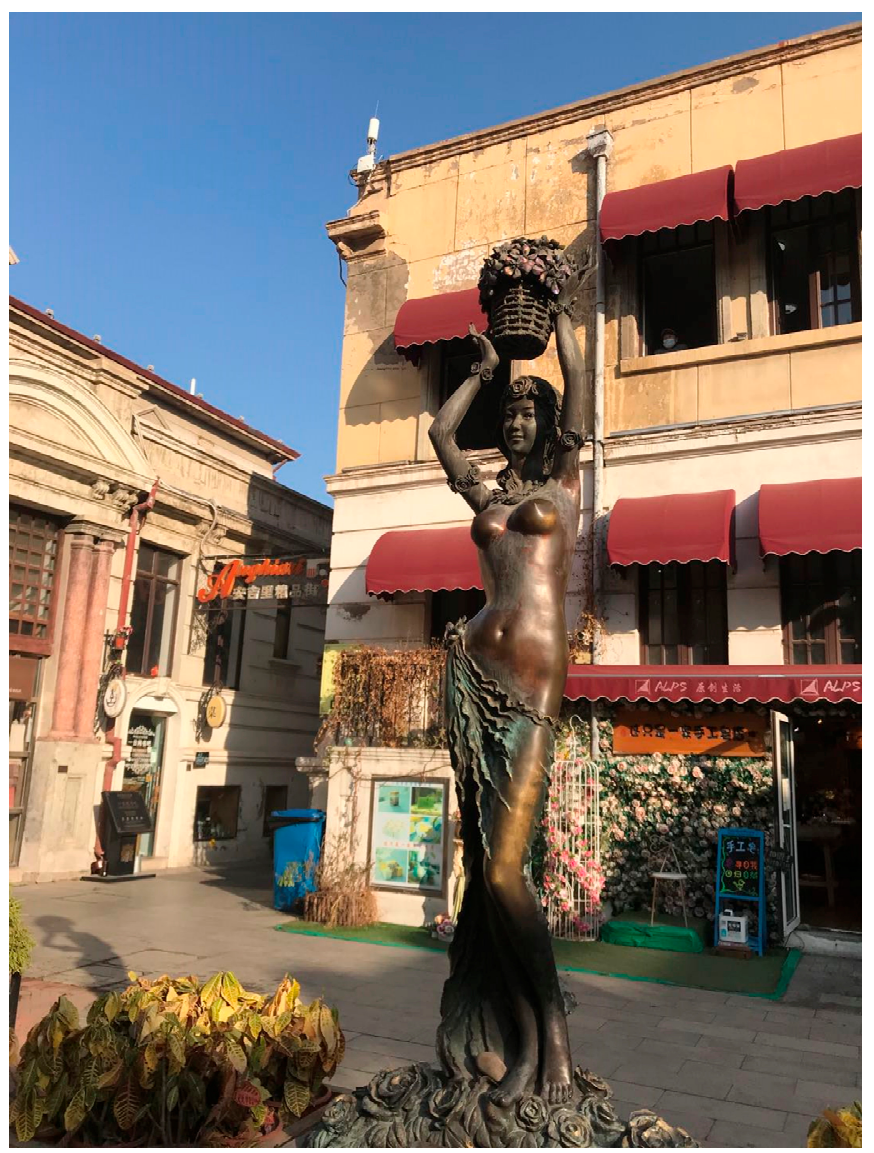

Figure 4. Flower Fairy. (The photo was taken by the author).

\subsection{Encountering a Lived Place in the Lifeworld}

Materials are visible and palpable, just as these magnificent buildings become traces of frozen history and gradually melt into the blood of the daily life of the city. In one place, all walks of people come and go, and different stories happen and are then forgotten. Marco Polo Plaza, like everywhere else, is thrown into a situation that already has meanings. Many of the tourists have done their homework before coming to visit and have some understandings, especially the local tourists who are willing to share their own experiences and stories about the place. One of the buildings most frequently mentioned is the former Italian barracks:

"Look at the building, the barracks, for the army, hidden in the narrow light path...look at the array of brick arches...aethereal...." (P21)

"My family has been in this neighbourhood for generations. Yes, there were Italian soldiers in the past. Later, the Japanese and the Kuomintang (the Nationalist Party) came. We could still hear the training bugles of the troops stationed in the 1980s... Now, the door is often closed here, as if it were the office of some company..." (P4)

Standing in the center of Marco Polo Plaza, a local pointed to an octagonal tower and introduced it to us:"It used to be Jai Alai Casino, the largest casino in the Italian concession, and now it's a cultural palace...look, there is a kindergarten next to it, my granddaughter's paradise. I have retired and often come to pick her up on weekdays, so I have plenty of time to hang around in the plaza...." (P4).

One visitor told us, "This is a very famous scene from movies and TV series. Yes, it is right here, Marco Polo Plaza. It's exactly the same as the scene in the movie. I'm just 
so impressed...." (P1). Apparently, he fulfilled his desire to visit a place of homologous emotion, a place that resonates with the plot of films he had watched.

One of the interesting things we found in the interviews was the embodiment. Visitors unfold the past and present of the place through visual and auditory descriptions, and tend to relate local stories to their own lived experiences. In this way, the place is no longer a sealed box; visitors are immersed in it, entangled with the material and immaterial here. It has diverse processes of production and succession due to the engagement of tourists who bring their own memories and perceptions [71,72]. Ideas, memories, and practices flow and merge, creating new place meanings. The exotic dress of this unique place is related to the daily life of the citizens, choreographing a place ballet in day-to-day activities [35].

\section{Discussion}

From the results, we find that visitors develop varying degrees of attachment and emotion when encounter with places, and diverse local meanings are generated that may act profoundly on the tension of sustainability. Thus, we discuss three points: wholeness, generation, and archive.

\subsection{Wholeness}

The discussion of the dichotomy in traditional place studies encourages the realization of the inevitability and necessity of understanding wholeness. In his works of the 1970s, Relph writes profusely about place and its related topics, involving place and placelessness, insiders and outsiders, center and edge, etc., the boundaries of which, either clear or vague, provide important references on landscape and identity. In this study, we believe that place and placelessness exist dialectically and are experienced holistically. Places are permeated and shaped by the socio-cultural characteristics of a far distant place, becoming a mixture of different histories and geographies. The encounter with the oriental Marco Polo Plaza is an encounter with exoticism and an encounter with daily life as well. It's a dwelling thinking that people-are-immersed-in-world-as-world-is-immersed-in-people [35]. The body, perceptions, and emotions extend beyond the self, making the whole environment a vast corporeality to experience and to be experienced. It is the place that thinks about us, not the place that we think about.

\subsection{Generation}

Place and placelessness are not static and predetermined, but generated; they shape the changing attitude and identity of tourists in the process of interdependence and transformation. For example, in urban planning, Marco Polo Plaza was labelled an "entertainment functional area". Informatization highlights these characteristics, widely spreads its unique features effectively, and stimulates and satisfies the curiosity of tourists who already have arrived or who will come to visit. However, excessive propaganda makes people tired and even resistant. A place gradually loses its texture and becomes mediocre in the midst of numerous messages, which leads to the weakening of its identity. Furthermore, commodity exchange and aesthetic taste are guided by globalization, so it is easy for us to obtain a taste of the change, disorder, dynamics and process suggested by Foucault. An authentic place is actively created and rebuilt, which is a subjective change that Cohen calls "emergent authenticity" [73].

\subsection{Archive}

The process of encountering is the process of archiving urban space. For example, from an individual perspective, place is mainly reflected in tourists' desire for and enjoyment of exoticism. To encounter is to experience the impact of landscape planning and design in urban public space on tourists' happiness. It also evokes and records space and communicates the connection between materials and urban practice. At the same time, materials and relations are compacted layer upon layer [74], such as the octagonal building changes from the casino during the concession period to the Workers' Cultural Palace. 
It can be seen that in this era, when we walk in and observe, the main preference of sustainability is to serve as a space for cultural leisure and urban tourism. Therefore, the research object of this article is mainly leisure tourists. These people are important, but not the only importance: they appear in a particular observed "window" of time and space, and they are agents with the connotation of sustainability in this era. The behavior of tourists and their associated economic, social, and cultural effects will become the important foundation for the people of the coming era (or "generation") to construct new connotations of sustainability. Therefore, tourists' experience and contextualization of travel processes are constantly archiving the transition between place and placelessness.

\section{Conclusions}

Taking Marco Polo Plaza in Tianjin, China, as an example, this paper discusses sustainability based on travel experiences in non-Western countries and re-examines the phenomenological concepts of place and placelessness anew. The results can be considered in three aspects: (1) encountering a place labelled recreation and entertainment, (2) encountering an exotic heterogeneous place, and (3) encountering a lived place in the lifeworld. This study highlights the important role of immersive phenomenological experience in exploring hybrid places and provides the possibility for the diversity of encounters.

It emphasizes that in the heterogeneous space of tourism, tourists capture the overlapping historical and cultural landscape and realize the interweaving of place and placelessness. That is, place and placelessness are intertwined paradoxically beyond the binary, and such a nonlinear, dialectical, and subtle dimension is the possible inspiration that the phenomenological perspective brings to tourism researches. It specifically proved the significance generated by the material environment of the tourist destination, the behavior and activities of tourists and meanings generated during the tour, tourists and places being as a whole. Then, the traditional tourist destination disappears. Tourists do not travel to a place, but travel through a place based on their own experiences. They embed themselves in the place, either as an insider or an outsider. For example, a person who lives in a place, but he/she is an "existential outsider" and remains deliberately detached from everything. Additionally, some may never return, but the air here will always stay in the memory.

Further, an open multisensory intervention and inclusive geographical practices are important approaches to enrich the dialectical understanding of sustainable tourism. The traditional sight-seeing tour has gradually been exchanged for a participatory and open visit that includes hearing, smell, touch, and other multi-senses. In addition, the change of tourism process from centralization to decentralization or polycenter may bring fragment experiences with which people, material, capital, technology, etc., are intertwined. As such, in precarious Anthropocene, the sustainable relationship between the human and nonhuman seems a huge issue [75]. Especially with the sudden COVID-19 pandemic, the travel flow is blocked, spontaneous or demanded lockdown is a responsible choice in a benign way, and the whole world seems to be a static frame as time passes [76-78]. The planned leisure areas only are left empty. The place, home, where people stay day to night has become a place of relaxation instead, and leisure places can be everywhere [79]. However, the limited space has been greatly extended by technology [80,81]. People pay attention to the Internet, and consumption, aesthetic, and daily life have been changed online. Going shopping through the keyboard, enjoying scenery through the screen, and satisfying the curiosity of the unknown land. Traditional tour has led to digital, many attractions have even launched panoramic online travel websites, which breaks through the existence of an object or object observed, and turns to be a potential field for the future tourism studies.

There remain some limitations to this article, especially with regard to the differences between the concept of place in the East and the West, which have not been fully explored in this article, although it provides a phenomenological perspective for capturing the tourism experience. Furthermore, the understanding of the tension between place and placelessness is still insufficient, particularly its dialectical relationship from the view of children and the 
aged. In addition, since the selection of the respondents and the interview data is inevitably subjective, the analysis process focuses mainly on materials as a representation. As a result, the marginalization of non-representational phenomena, such as practice, performance, an unrecorded stream of consciousness, symbols, and imagination, arousal, has become a limitation of the entire process. Perhaps what goes unrecorded is what is truly meaningful and worthwhile in place studies.

Author Contributions: Writing original draft, H.G.; review and editing, S.Z.; map made by S.Z.; photos taken by H.G. Both authors have read and agreed to the published version of the manuscript.

Funding: National Natural Science Foundation of China: 41771148.

Acknowledgments: We wish to thank Xiaoming, Xiaofang, Alessandra, Isabella, and editors who engaged. We are also thankful to the anonymous reviewer for her or his constructive critical comments with this manuscript.

Conflicts of Interest: The authors declare no conflict of interest.

\section{References}

1. Sauer, C.O. The morphology of landscape. In Land and Life: A Selection from the Writings of Carl Ortwin Sauer; Leighly, J., Ed.; The University of California Press: Berkeley, CA, USA, 1967; p. 320. ISBN 0-631-19459-2.

2. Todres, L. Clarifying the life-world: Descriptive phenomenology. In Qualitative Research in Health Care; Holloway, I., Ed.; Open University Press: Berkshire, UK, 2014; pp. 104-122. ISBN 9780335212934.

3. Moran, D. Introduction to Phenomenology; Routledge: London, UK, 2000; ISBN 9780415183734.

4. Selby, M.; Hayllar, B.R.; Griffin, A.R. The tourist experience of precincts. In City Spaces—Tourist Places: Urban Tourism Precincts; Hayllar, B., Griffin, T., Edwards, D., Eds.; Butterworth-Heinemann: Oxford, UK, 2008; pp. 183-202. ISBN 9780750681957.

5. Tuan, T.-F. Topophilia, or sudden encounter with landscape. Man, Space, and Environment; English, P., Mayfield, R., Eds.; Oxford University Press: Oxford, UK, 1972; pp. 534-538. ISBN 9780195014419.

6. Seamon, D. Place attachment and phenomenology. In Place Attachment: Advances in Theory, Methods and Applications; Manzo, L., Devine-Wright, P., Eds.; Routledge: New York, USA, 2014; pp. 11-22. ISBN 9780429274442.

7. Mccabe, S.; Stokoe, E.H. Place and identity in tourists' accounts. Ann. Tourism Res. 2004, 31, 601-622. [CrossRef]

8. Wylie, J. Landscape; Routledge: New York, NY, USA, 2007; ISBN 9780415341431.

9. Williams, A.M.; Baláž, V. Tourism risk and uncertainty: Theoretical reflections. J. Travel Res. 2014, 54, 271-287. [CrossRef]

10. Chen, X. A phenomenological explication of guanxi in rural tourism management: A case study of a village in China. Tour. Manag. 2017, 63, 383-394. [CrossRef]

11. Ryan, C. Sex tourism: Paradigms of confusion? In Tourism and Sex: Culture, Commerce and Coercion; Clift, S., Carter, S., Eds.; Pinter: London, UK, 2000; pp. 23-40. ISBN 1855675498.

12. Lew, A.A. Understanding experiential authenticity through the best tourism places. Tourism Geogr. 2011, 13, 570-575. [CrossRef]

13. Relph, E. Place and Placelessness; Pion: London, UK, 1976; ISBN 9780850860559.

14. Augé, M. Non-places: Introduction to the Anthropology of Supermodernity; Verso: London, UK, 1995; ISBN 1-85984-956-3.

15. Relph, E. A pragmatic sense of place. In Making Sense of Place; Vanclay, F., Higgins, M., Blackshaw, A., Eds.; National Museum of Australia: Canberra, Australia, 2008; ISBN 9781876944513.

16. Wassler, P.; Kuteynikova, M. Living travel vulnerability: A phenomenological study. Tour. Manag. 2019, 76. [CrossRef]

17. Relph, E. The paradox of place and the evolution of placelessness. In Place and Placelessness Revisited; Freestone, R., Liu, E., Eds.; Routledge: New York, USA, 2016; ISBN 9780815381990.

18. Bender, B. Time and landscape. Curr. Anthropol. 2002, 8, 43-103. [CrossRef]

19. Cameron, J. Changing Places: Re-imagining Australia; Longueville Books: Sydney, Australia, 2003; p. 309. ISBN 9781920681067.

20. Tuan, Y.F. Topophilia: A Study of Environmental Perceptions, Attitudes, and Values; Columbia University Press: New York, NY, USA, 1990; ISBN 0231073941.

21. Muñoz, C.L.; Wood, N.T. A recipe for success: Understanding regional perceptions of authenticity in themed restaurants. Intl. J. Cult. Tour., Hosp. Res. 2009, 3, 269-280. [CrossRef]

22. Varley, P.; Schilar, H.; Rickly, J.M.; Tribe, J. Tourism non-places: Bending airports and wildscapes. Ann. Touris. Res. 2020, 80. [CrossRef]

23. Seamon, D. Place, placelessness, insideness, outsideness in John Sayles' Sunshine State. Aether: J. Media Geogr. 2008, 3, 1-19.

24. Hao, X.; Zhang, X.; Mai, P. Anime pilgrimage tourists' behavioral patterns and their homologous affection: Taking anime film Your Name as an example. Tour. Tribune 2020, 35, 95-108. [CrossRef]

25. Hartshorne, R. Perspectives on the Nature of Geography; Rand McNally: Chicago, IL, USA, 1959; ISBN 9781258337247.

26. Dwyer, L.; Chen, N.C.; Lee, J.J. The role of place attachment in tourism research. J. Travel Tour. Mark. 2019, 36, 645-652. [CrossRef]

27. Lee, S.; Joo, D.; Lee, C.-K.; Woosnam, K.M. Korean DMZ tourists' perceived similarity and shared beliefs in predicting place attachment and support for tourism development. J. Destin. Mark. Manag. 2020, 18, 100467. [CrossRef] 
28. Yuan, Q.; Song, H.; Chen, N.; Shang, W. Roles of Tourism Involvement and Place Attachment in Determining Residents' Attitudes Toward Industrial Heritage Tourism in a Resource-Exhausted City in China. Sustainability 2019, 11, 5151. [CrossRef]

29. Aleshinloye, K.D.; Fu, X.; Ribeiro, M.A.; Woosnam, K.M.; Tasci, A.D. The Influence of Place Attachment on Social Distance: Examining Mediating Effects of Emotional Solidarity and the Moderating Role of Interaction. J. Travel Res. 2020, 59, 828-849. [CrossRef]

30. Schilar, H.; Keskitalo, E.C.H. Tourism activity as an expression of place attachment-place perceptions among tourism actors in the Jukkasjärvi area of northern Sweden. Scand. J. Hosp. Tour. 2017, 18, S42-S59. [CrossRef]

31. Shim, C.; Santos, C.A. Tourism, place and placelessness in the phenomenological experience of shopping malls in Seoul. Tour. Manag. 2014, 45, 106-114. [CrossRef]

32. Rowley, J.; Slack, F. The retail experience in airport departure lounges: Reaching for timelessness and placelessness. Int. Mark. Rev. 1999, 16, 363-376. [CrossRef]

33. Hayllar, B.; Griffin, T. The precinct experience: A phenomenological approach. Tour. Manag. 2005, 26, 517-528. [CrossRef]

34. Tuan, Y.F. Geography, Phenomenology, and the Study of Human Nature. Can. Geogr. 2008, 15, 181-192. [CrossRef]

35. Relph, E. An inquiry into the relations between phenomenology and geography. Can. Geogr. 1970, 14, 193-201. [CrossRef]

36. Buttimer, A. Grasping the dynamism of lifeworld. Ann. Assoc. Am. Geogr. 1976, 66, 277-292. [CrossRef]

37. Seamon, D. Dwelling, Place, and Environment: Towards a Phenomenology of Person and World; Martinus Nijhoff: Dordrecht, The Netherlands, 1985; ISBN 9789024731923.

38. Seamon, D. A Geography of the Lifeworld; CroomHelm: London, UK, 1979; ISBN 9781138885073.

39. Rybråten, S.; Skår, M.; Nordh, H. The phenomenon of walking: Diverse and dynamic. Landsc. Res. 2017, 1-13. [CrossRef]

40. Ingram, G. Motivations of farm tourism hosts and guests in the south west tapestry region, Western Australia: A phenomenological study. Indo Pac. J. Phenomenol. 2002, 2, 1-12. [CrossRef]

41. Berdychevsky, L.; Gibson, H. Phenomenology of young women's sexual risk-taking in tourism. Tour. Manag. 2015, 46, 299-310. [CrossRef]

42. Blaer, M.; Frost, W.; Laing, J. The future of travel writing: Interactivity, personal branding and power. Tour. Manag. 2020, 77, 104009. [CrossRef]

43. Wassler, P.; Schuckert, M. The lived travel experience to North Korea. Tour. Manag. 2017, 63, 123-134. [CrossRef]

44. Marinelli, M. The genesis of the Italian concession in Tianjin: A combination of wishful thinking and realpolitik. J. Mod. Ital. Stud. 2010, 15, 536-556. [CrossRef]

45. Marinelli, M. The Triumph of the uncanny: Italians and Italian architecture in Tianjin. Cult. Stud. Rev. 2013, 19, 70-98. [CrossRef]

46. Marinelli, M. Making concessions in Tianjin: Heterotopia and Italian colonialism in mainland China. J. Urban Hist. 2009, 36, 399-425. [CrossRef]

47. Chauffert-Yvart, B.; Ged, F.; Lu, Y.; Mengin, C.; Rousseau, É. Tourism and heritage in the enhancement of Tianjin. Built Herit. 2020, 4, 1-12. [CrossRef]

48. The State Council of China. The Reply to the Urban Master Plan of Tianjin. Letter of the State [1986] No.92. Available online: http:/ / www.gov.cn/xxgk/pub/govpublic/mrlm/201207/t20120706_65307.html (accessed on 1 May 2021).

49. Merriam, S.; Grenier, R. Qualitative Research in Practice: Examples for Discussion and Analysis, 2nd ed.; Josser-Bass: San Francisco, CA, USA, 2019; ISBN 9781119452027.

50. Vagle, M.D. Crafting Phenomenological Research, 2nd ed.; Routledge: New York, NY, USA, 2018; ISBN 9781138042650.

51. Dahlberg, K.; Dahlberg, H.; Nyström, M. Reflective Lifeworld Research, 2nd ed.; Studentlitteratur: Lund, Sweeden, 2008; ISBN 9144049250.

52. Christian, M. Protecting tourism labor? Sustainable labels and private governance. Geojournal. 2017, 82, 805-821. [CrossRef]

53. Marcotte, P.; Bourdeau, L. Is the World Heritage label used as a promotional argument for sustainable tourism? J. Cult. Herit. Manag. Sustain. Dev. 2012, 2, 80-91. [CrossRef]

54. Vannini, P.; Stewart, L.M. The GoPro gaze. Cult. Geogr. 2017, 24, 149-155. [CrossRef]

55. Hoffmann, L.M.; Fainsteun, S.S.; Judd, D.R. (Eds.) Cities and Visitors: Regulating People, Markets and City Space; Blackwell: Oxford, UK, 2003; ISBN 9780470773673.

56. Hall, S. Representation: Cultural Representations and Signifying Pracices; SAGE: London, UK, 1997; ISBN 7-100-03573-2/G·477.

57. Putra, I.N.D.; Verheijen, B.; Ardika, I.W.; Yanthy, P.S. Affinity tourism and exotic tourism in bali. The Chinese and Indian tourist gaze in the Garuda Wisnu Kencana Park. J. Tour. Cult. Chang. 2020, 1-17. [CrossRef]

58. Everett, S. Production Places or Consumption Spaces? The Place-making Agency of Food Tourism in Ireland and Scotland. Tour. Geogr. 2012, 14, 535-554. [CrossRef]

59. Kamat, S. Exotic Village Tourism: Case Study of Saligao and Candolim. Int. J. Hosp Tour. Syst. 2011, 4, 75-86.

60. Fernandes, L. The politics of forgetting: Class politics, state power and the restructuring of urban space in India. Urban Stud. 2004, 41, 2415-2430. [CrossRef]

61. Harvey, D. The Condition of Postmodernity. Blackwell: Oxford, UK, 1989; ISBN 0631162925.

62. Snepenger, D.; Snepenger, M.; Dalbey, M.; Wessol, A. Meanings and Consumption Characteristics of Places at a Tourism Destination. J. Travel Res. 2007, 45, 310-321. [CrossRef]

63. Meethan, K. Tourism in Global Society: Place, Culture, Consumption; Palgrave: Basingstoke, UK, 2002 ; ISBN 9780333760581.

64. O'Brien, L.; Harris, F. Retailing: Shopping, Society, Space; David Fulton Publishers: London, UK, 1991 ; ISBN 9780415540407. 
65. Jewel, N. The fall and rise of the British mall. J Archit. 2001, 6, 317-378. [CrossRef]

66. Levine, M. Downtown redevelopment as an urban growth strategy: A critical appraisal of Baltimore renaissance. J. Urban Aff. 1987, 9, 103-123. [CrossRef]

67. Richards, G. Production and consumption of European cultural tourism. Ann. Touris. Res. 1996, 23, 261-283. [CrossRef]

68. Han, B.-C. The Burnout Society; Stanford University Press: Palo Al, CA, USA, 2015; ISBN 9780804795098.

69. Strannegard, L.; Strannegard, M. Works of art: Aesthetic ambitions in design hotels. Ann. Touris. Res. 2012, 39, 1995-2012. [CrossRef]

70. Ksenia, K. Destination aesthetics and aesthetic distance in tourism experience. J Travel Tour. Mark. 2014, 32, 1051-1068. [CrossRef]

71. Andrew, D. Experiential places or places of experience? Place identity and place attachment as mechanisms for creating festival environment. Tour. Manag. 2016, 55, 49-61. [CrossRef]

72. Lazzari, M.; Korstanje, A. The past as a lived space: Heritage places, re-emergent aesthetics, and hopeful practices in NW Argentina. J. Soc. Archaeol. 2013, 13, 394-419. [CrossRef]

73. Cohen, E. Authenticity and Commoditization in Tourism. Ann. Touris. Res. 1988, 15, 371-386. [CrossRef]

74. Sheringham, M.; Wentworth, R. City as archive: A dialogue between theory and practice. Cult. Geogr. 2016, 23, 517-523. [CrossRef]

75. Malone, K.; Truong, S.; Gray, T. Reimagining Sustainability in Precarious Times; Springer: Singapore, 2017.

76. Fermani, A.; Sergi, M.; Carrieri, A.; Crespi, I.; Picconi, L.; Saggino, A. Sustainable Tourism and Facilities Preferences: The Sustainable Tourist Stay Scale (STSS) Validation. Sustainability 2020, 12, 9767. [CrossRef]

77. Cavagnaro, E.; Staffieri, S.; Carrieri, A.; Burns, K.; Fermani, A. Profiling for sustainable tourism: Young travellers' selftranscendence values and motivations. Eur. J. Touris. Res. 2021, 28, 2810.

78. Ren, X. Pandemic and lockdown: A territorial approach to COVID-19 in China, Italy and the United States. Eurasian Geogr. Econ. 2020, 61, 423-434. [CrossRef]

79. Bond, A.J.; Widdop, P.; Cockayne, D.; Parnell, D. Prosumption, Networks and Value during a Global Pandemic: Lockdown Leisure and COVID-19. Leis. Sci. 2020, 1-8. [CrossRef]

80. Das, D.; Zhang, J. Pandemic in a smart city: Singapore's COVID-19 management through technology \& society. Urban Geogr. 2020. [CrossRef]

81. Iranmanesh, A.; Alpar Atun, R. Restricted Spatiality and the Inflation of Digital Space, an Urban Perspective. Space Cult. 2020, 23, 320-328. [CrossRef] 